\section{FISHERMEN OF THE CARIBBEAN: INFORMALITY, THE RIGHT TO OCCUPATIONAL HEALTH AND THE INTERVENTION OF PUBLIC POLICIES}

${ }^{1}$ I Bello*, ${ }^{2}$ A Salmen-Navarro. 'Simon Bolivar University, Venezuelan Society on Occupational Health, Caracas, Venezuela: ${ }^{2}$ New York University, New York, USA

\subsection{6/oemed-2018-ICOHabstracts.1419}

Introduction The right to life and health of fishermen is enshrined in the Constitution and labour laws, but in practice this right is not exercised effectively, since there is no formal employee-employer relationship. This study sought to establish the health conditions of this population, to characterise the mechanisms through which their rights can be realised and to propose interventions in the public policies that can facilitate their execution.

Methods The first part was based on a sampling of four fishing zones of the Venezuelan Caribbean, with a total sample of 455 active fishermen, characterising labour risks and health conditions. The second part consisted of a description of the normative set, from the Constitution, the Law of Occupational Health and the Law of Fishing, complemented with interviews with authorities of National Fishing Institute.

Results The most prevalent health conditions were musculoskeletal upper limb disorders and left unilateral hearing loss. In reference to the occupational health system, there was a total lack of application of the rights enshrined in the regulation, but it cannot be applied due to the absence of a formal working relationship, with the consequent lack of coercive regime and the inapplicability of fines or infringements for breach.

Conclusion Fishermen in the region are not protected by national regulations on occupational health and safety, which is why they have a high rate of involvement due to pathologies of occupational origin. There is a great opportunity to positively influence this situation, including postulates related to occupational health and safety in the regulations of the Fisheries Act, and incorporating items of protection to the health of fishermen in the fishery inspection procedure, in charge of granting the territorial catch concessions to the shipowners.

\section{\begin{tabular}{|l|l}
\hline 73 & WORKPLACE INTERVENTION AND RESEARCH IN
\end{tabular} CONTRACT WOMEN WORKERS}

${ }^{1}$ Sashikala Chandrasekar, ${ }^{2}$ Jayashree Vijayakumar. ${ }^{1}$ Private sector, Bangalore, India; ${ }^{2}$ Private sector, Chennai, India

\subsection{6/oemed-2018-ICOHabstracts. 1420}

Introduction Iron deficiency anaemia in working women is common and is more prevalent in women contract workers. Work place intervention with participatory approach to contract workers' health and well-being gives a positive outcome as seen in this study.

Methods Consent was obtained from company management and volunteers. Duration of study was six months. 100 women contract workers were selected in age group 20-45. In the first month clinical history, baseline haemoglobin estimation, dispensation of 30 tablets each of iron with folic acid and multivitamins and diet education was done. 2nd to 6th month, tablets dispensation and diet education was continued. Tablet albendazole for deworming given in first and fourth month. Diet education conducted with charts/posters with details of food containing iron and vit.c. After six months, haemoglobin estimation was done and results were compared.
Results Base line haemoglobin findings showed 9\%-not anaemic, 27\%-mildly anaemic, 53\%-moderately anaemic and 11\%severely anaemic. $\mathrm{Hb} \%$ above $11 \mathrm{~g} / \mathrm{dl}$ was taken as not anaemic. Results at the end of study showed increase in $\mathrm{Hb} \%$ level, 31\%-not anaemic, 48\%-mildly anaemic, 19\%-moderately anaemic, and 2\%-severely anaemic. $\mathrm{Hb} \%$ above12 $\mathrm{g} / \mathrm{dl}$ was not observed in anyone in 1 st month and after 6 months intervention $7 \%$ were above $12 \mathrm{~g} / \mathrm{dl}$. At the end of study period overall improvement in health was noted. Health complaints like tiredness, myalgia, gynaecological problems were less. General health and well-being improved, absenteeism decreased and few persons increased in weight.

Conclusion Contract workers have lower income and fewer benefits like leave and facilities. They continue working at the cost of their health, especially when they have to support their family. Malnourishment and anaemia in reproductive age group leads to increased maternal and infant mortality and morbidity. Workplace interventions as welfare measures in informal sector workers will produce healthy workforce with good physical capacity and thereby productivity of company will increase.

\section{NON-COMMUNICABLE DISEASE PREVENTION THROUGH SELF-MANAGEMENT APPROACH AMONG INFORMAL WORKERS: A CASE STUDY IN BANGKOK, THAILAND}

N Chantra*, N Changchai. Faculty of Public Health and Environment, Huachiew Chalermprkiet University, A.Bangplee, Samut Prakarn, Thailand

\subsection{6/oemed-2018-ICOHabstracts. 1421}

Introduction The informal workers in Bangkok had inequity in social welfare and employment security, and they were the lowest group of happiness level than another area. Some of them were living with Non-Communicable Diseases (NCD). Therefore, this study aims to improve health status of the NCD informal workers by applying self-management method.

Method This study composed of quantitative and qualitative studies. The 15 informal workers were included by criteria. They were participated in the Mental health improvement project, had NCD risks or NCD patients, living in Bangkok, and willing to improve health status. The Participatory-action research was applied in this study by giving the knowledge of self-management (composed of 1) appropriate sleep 2) long breathing 3) reduce dessert consumption 4) do light physical activity) and relevant knowledge (including environmental improvement, finding assistant, finding more knowledge, making inspiring sentence, and self-rewarding). The progressive of health status were collected by in-depth interview and selfadministrative questionnaire during June, 2015-October, 2016. The nonparametric statistics was applied in data analysis.

Results After all subjects were trained in self-management, they set up their target plan and followed it periodically. The results showed that 4 Diabetes Mellitus workers succeed in control of weight and blood sugar and 1 could maintain her weight. One worker with Diabetes Mellitus and Hyperlipidemia, 3 workers with Hypertension, and 3 Over-weight adults succeed in weight control, 2 workers with Cancer could live without any progressive of cancer, 1 worker with Coronary Heart disease succeed in weight control and had better heath check up. Their stress score were reduced significantly (pvalue $=0.01$ ), and their happiness score become increased. 
Discussion Self-management and relevant knowledge are the important preventive factors of NCD prevention and there should be combined with the effective follow-up measure. However, this finding should be applied in large scale or in community.

\section{USING ETHNOGRAPHIC INTERVIEWS TO FACILITATE A PARTICIPATORY ERGONOMICS STUDY AMONG HOME- BASED MAPUCHE WEAVERS IN SOUTHERN CHILE}

${ }^{1} \mathrm{G}$ Gracia*, ${ }^{2} \mathrm{~A}$ Guzman, ${ }^{3} \mathrm{~L}$ Forst. ${ }^{1}$ University of Illinois at Chicago, Chicago, USA; ${ }^{2}$ MAPLE Micro Development, Temuco, Chile; ${ }^{3}$ University of Illinois At Chicago, Chicago, Illinois, USA

\subsection{6/oemed-2018-ICOHabstracts. 1422}

Introduction While there is extensive literature on ergonomic hazards related to weaving, research on implementing interventions is limited. The Mapuche represent Chile's largest indigenous population and weaving represents an important source of income for women. While home-based work allows for flexible scheduling, it can also lead to working long hours, difficulty balancing professional and domestic responsibilities and greater occupational health issues. Participatory approaches have proven successful in addressing occupational health problems, however, there is scant research related to home-based artisans.

Methods A convenience sample of 35 home-based Mapuche weavers in Southern Chile were recruited for the study. Of these, 10 participated in ethnographic interviews. Purposive sampling was used to obtain a representative sample across communities, identified health issues; workspace type; and years of weaving experience. Semi-structured interviews were conducted in the weavers' homes along with videos, photograph and written observations of the weaving workspaces. The interviews focused on workday organisation; weaving workspace; self-identified health issues, perceived causes and potential solutions to hazard prevention. Data were analysed using Atlas.ti.

Results Each interview yielded a 'day-in-the-life' visual. This graphic model helped facilitate discussions around time management, health issues, potential causes and treatment. In addition to weaving, participants identified farm work $(n=9)$, housework $(n=9)$, wool production $(n=7)$ and dyeing $(n=7)$ as tasks that caused health issues. Respondents identified weaving as the cause of eyestrain $(n=7)$, back $(n=6)$, shoulder $(n=5)$ and hand pain $(n=4)$. Interventions identified, implemented and currently being evaluated include: provision of eye exams, a kinesiologist workshop and provision of headlamps.

Conclusion This project demonstrates the importance of using ethnographic methods to strengthen participatory approaches to artisan occupational health. The data provided unique insight into the complex relationship between home-based work, health and sustainable interventions. This work yielded a culturally appropriate methodology that can be applied to other home-based artisans.

\section{WORK EQUIPMENT AND UNSAFE USE IN MICRO AND SMALL ENTERPRISES}

${ }^{1}$ Filip Pelgrims*, ${ }^{2}$ Hilde De Raeve, ${ }^{3}$ Marc Beurms. ${ }^{1}$ Product manager SME segment Group IDEWE, Leuven, Belgium; ${ }^{2} M D$ PhD Research department Group IDEWE, Leuven, Belgium; ${ }^{3}$ CIO and CFO Group IDEWE, Leuven, Belgium/Chairman of the dataforce of Belgian OSH services

10.1136/oemed-2018-ICOHabstracts. 1423
Aim The detection of unsafe handling with work equipment in small and micro enterprises.

Introduction A well elaborated occupational safety and health policy is crucial, yet, can micro and small scaled enterprises (MSE's) develop a good safety program, according working with workequipment?

Methods Idewe, a Belgian external service for prevention and protection at work, uses the online risk-assessment tool 'BRIE (i.e. Better Risk Inventarisation and Evaluation) to guide occupational health and safety experts during periodic company visits. BRIE risk-assessments were performed in a convenience sample of MSE's during the period 2015-2016. A selection of questions about safety handling $(n=6)$ was assessed. Examples are:

- Has the employer already made an inventory of the workingequipment?;

- Are there good safetyinstructions for all work equipments?;

- Have the employees been trained on safe use of work equipment?

Only the MSE's where all safety factors (work equipmentrelated) were scored, were included for analysis. Prevalences were calculated using frequencies.

Results Brie provides, 1/a list of important sector specific OSH issues (e.g. workequipment), 2/advice regarding good practices, legal information and preventive actions and 3) an evaluation of sector specific occupational risks. Data was available from 1950 MSE's. About 59\% of the companies, did not have an inventory of there workequipment. 53\% of the companies did not have any instruction for there working-equipment. Only $33 \%$ scored positive on training or education of there employees about safe use of their work equipment.

Discussion Brie risk-assessments reveal that assessments and policies regarding safe use of working equipment is non-existing in a significant number of MSE's. MSE's therefore need extra support, information, and advise.

\section{Thermal Factors}

\section{THE EFFECTIVENESS OF DAYTIME BATH AMONG NEW CONSCRIPTS IN A TRAINING UNIT FOR HEAT INJURY PREVENTION}

${ }^{1}$ Kathawoot Deepreecha*, ${ }^{2}$ Wittaya Seehabun, ${ }^{3}$ Boonterm Saengdidtha. ${ }^{1}$ Health Promotion and Preventive Medicine Division, Royal Thai Army Medical Department, Bangkok, Thailand; ${ }^{2}$ Third Medical Battalion, Third Infantry Division, Nakornratchasima, Thailand; ${ }^{3}$ Outpatient Department, Phramongkutklao Hospital, Bangkok, Thailand

\subsection{6/oemed-2018-ICOHabstracts. 1424}

Introduction Heat injury is a common illness among new conscripts during basic training course in Thailand and heat stroke is a major cause of death. There are a lot of methods to reduce the body temperature of conscripts to prevent heat injury. The conscripts are allowed to take a bath in the evening every day as regular bath during training. Daytime bath is one of the procedures. The objective of this study is to compare the effectiveness between daytime bath and regular bath for heat injury prevention among new conscripts in training unit.

Methods A quasi-experimental study was conducted in 93 new conscripts in training unit. The data of their body temperature before and after daytime bath in the time of 1200 and 0300 